\title{
O PARADOXO DOS DIREITOS HUMANOS
}

\author{
THE PARADOX OF HUMAN RIGHTS
}

\section{Juliana Neuenschwander Magalhães*}

RESUMO: Os direitos humanos são construções artificiais que, desde o século dezoito, oferecem, ao mesmo tempo, uma explicação para a fundação do direito e da política: sua função é oferecer uma base para sistemas que, de fato,não tem base alguma. Uma observação da semântica e da estrutura dos direitos humanos nos permite observar seu caráter paradoxal e, especialmente, a forma através da qual esse paradoxo pode ser desenvolvido de uma maneira criativa.

PALAVRAS-CHAVE: Direitos humanos. Paradoxo. Sistema.

ABSTRACT: Human rights are artificial constructs that, since the 18th century,offer an explanation for the foundation of law and politics at the same time: its function is that of providing a basis for systems that actually have no basis. An observation of semantics and structure of human rights allows us to observe its paradoxical character and especially the way in which this paradox can be developed in a creative way.

KEYWORDS: Human rigths. Paradox. System.

\footnotetext{
* Professora Associada da UFRJ. Pesquisadora do CNPQ. E-mail: jneuewander@yahoo.com.br
} 
A história dos direitos humanos é resultado de um complexo processo históricosemântico, no curso do qual as mudanças sociais criaram a necessidade de se encontrar novas formas de descrição da sociedade. A fórmula direitos humanos recolhe o plexo de transformações ocorridas na Modernidade e consiste, como a seguir procuraremos demonstrar, numa reação à forma moderna de diferenciação social. Os direitos humanos, neste passo, constituem um novo fundamento para uma sociedade que, na Modernidade, está em crise com os fundamentos.

Especificamente, o direito e a política modernos encontram nos direitos a representação de sua fundação ou, ainda, os pressupostos de sua fundação, uma espécie de fundamento dos fundamentos. Assim, até que se chegasse ao momento em que os direitos humanos fossem direitos declarados e, portanto, reconhecidos como tais de forma positivada, séculos de experiência histórica e semântica foram condensados na forma de novas teorias, cuja complexidade cuidava de ocultar, na novidade dos direitos, o velho paradoxo das fundações que não conhecem fundação.

As apresentações de uma história dos direitos, em geral, não se ocupam de pesquisar os problemas sociais que se pretendeu solucionar pelo recurso às teorias do direitos humanos. Os direitos são tratados, do ponto de vista tanto histórico quanto teórico, como algo ontologicamente dado: e é assim que se fala, por exemplo, em "gerações" de direitos humanos. Nesse passo, a pesquisa se volta para a busca dos "avós" dos atuais direitos humanos, e dos avós daqueles, e assim sucessivamente... Desde essa perspectiva, encontram-se na literatura pelo menos duas genealogias, ou seja, duas diferentes tradições, desde as quais se construiu a moderna noção de direitos humanos: a tradição inglesa e americana, de um lado, e, de outro, a tradição francesa.

Aqui, não trataremos de tentar apontar a primazia e originalidade de uma dessas tradições sobre a outra, tomando partido em disputas como aquela que, no século passado, travaram Jellinek e Boutmy (JELLINEK, 1908). Nossa hipótese é de que a evolução de uma semântica dos direitos humanos, e isso tanto no contexto anglo-saxão quanto no contexto continental europeu, representam tentativas equifinais de se procurar solução para problemas que não eram localizados espacial ou temporalmente. Exatamente por isso, os direitos humanos não podem ser explicados pela referência nem à história do common law inglês ou da independência norte-americana, do mesmo modo que não podem ser explicados pelo relato histórico dos eventos que resultaram na Revolução Francesa e na posterior Declaração dos Direitos do Homem e do Cidadão de 1789.

Nessa direção, um olhar sobre as especificidades de cada uma daquelas supostamente diferentes tradições interessa-nos apenas na medida em que é capaz de desvelar a universalidade dos problemas que a semântica dos direitos humanos veio, na sociedade moderna, solucionar. ${ }^{1}$ A universalidade dos problemas consiste no fato de que esses são problemas de uma só sociedade, a sociedade do mundo. Não se pode

1 Para uma comparação das duas tradições, v. STOURZH, 1979, p. 347-364. 
confundir, portanto, essa universalidade de problemas com aquilo que a tradição chamou de universalidade dos direitos humanos.

$\mathrm{Na}$ discussão inglesa e americana, o caráter universal dos direitos humanos foi deduzido da tradição do common law, o que não deixa de representar, para nós, uma curiosidade: a universalidade e a historicidade dos direitos humanos foram, paradoxalmente, espaciais e historicamente fundadas. Os direitos de liberdade eram os bons e velhos direitos do direito inglês, cujas fontes poderiam ser tão longínquas como a Magna Charta de 1215. Esses documentos declaravam "the birthright of the people of England", de acordo com a antiga doutrina do common law. Mas, na construção de Blackstone acerca desse problema, esses direitos já não são exclusivos dos ingleses, dado que constituem um "resíduo da liberdade natural" de todo homem. Esses direitos, concebidos como "resíduos do direito natural", todavia deveriam ser declarados, explica Blackstone, justamente porque foram destruídos na maior parte do mundo: "There therefore were formerly, either by enheritance or purchase, the rights of all mankind; but, in most other countries of the world being now more or less debased and destroyed, they at present may be said to remain, in a peculiar and particular manner, the rights of the people of English". (BLACKSTONE, 1966, p. 125)

Já a tradição francesa manteve-se apegada à ideia de direitos humanos como direitos naturais, não obstante o fato de que, após a Revolução, providência imediata tenha sido a de proceder, na Assembleia Nacional, à declaração dos mesmos. Mais tarde, em decorrência do próprio texto de 1789 , tornou-se imprescindível a constitucionalização dos direitos humanos: “Toute societé, dans laquelle la garantie des droits n'est pas assurée, ni la séparation des pouvoirs déterminée, n'a point de constitution", rezam os termos do artigo 16 da referida Declaração. A constitucionalização dos direitos humanos, a partir daí indicados como direitos fundamentais, sucedeu, portanto, sua fundamentalização, antecipada como, paradoxalmente, condição e resultado das revoluções. Os alemães chamaram o processo de incorporação dos direitos naturais nos textos constitucionais, conforme Stourzh, de "positivierung des Naturrechts", significando com isso a tranformação das normas de direito natural em normas legais aplicáveis, estabelecida a Constituição como paramount law. (STOURZH, 1979, p. 350) ${ }^{3}$ Essa positivação, ou constitucionalização, não exclui, entretanto, que sobretudo na tradição inglesa, muitos desses direitos já houvessem sido fundamentalizados.

2 "Thus much for the declaration of our rights and liberties. The rights themselves thus defined by these several statutes, consist in a number of private immunities (...) than either that residuum of natural liberty". (BLACKSTONE, 1966, p. 125).

3 O autor menciona a decisão de um juiz de Massachussetts, no caso Quok Walker, de 1783. Naquele caso, o Chief Justice declarou que a escravidão, tolerada por muito tempo em Massachussetts, não mais poderia sê-lo, pois encontrava-se em contradição com a Constituição daquele Estado, dado que o art. 1 da Declaration of Rights of the Inhabitants of Massachussets declarava que "all men are born free and equal, and possessed certain natural essential and inalienable rights". 
1.

Na base de ambas as tradições, a francesa e a do common law, encontrava-se uma ideia que era ambígua e precária: a noção de contrato como explicação da fundação do direito e da política. Uma visão contratualista da fundação do direito e da política era tradicional já no contexto do common law, com suas raízes feudais e seu apego ao princípio do pacta sunt servanda. Na tradição continental-europeia, por sua vez, a noção de contrato social foi uma solução para o problema oriundo da Reforma, qual seja, aquele de encontrar uma fundação não religiosa num mundo que conhece duas religiões. Naquele período, os conflitos que surgiam entre a ordem jurídica e o domínio político já diferenciados eram regulados por meio da forma legal do contrato (que, naquela situação, era interpretado como se houvesse ocorrido há muito tempo). A necessidade de uma explicação jurídica para a fundação da política, que se traduz na ideia de contrato social evidencia, por si só, o processo de diferenciação de direito e política característico da Modernidade. Só neste momento, em que se constituem como contextos sociais diferenciados, direito e política podem apoiar-se reciprocamente.

Na ideia de contrato social a tríade liberdade-igualdade-propriedade foi conjugada, sendo esses os pressupostos, naturais, da juridicidade do contrato. A fórmula do contrato, porém, ao mesmo tempo em que era produto da moderna diferenciação de direito e política, revelava-se fragilizada, precisamente, em face dessa diferenciação. Uma vez que foi pensado como a unidade jusnaturalista de direito e política, o contrato confrontavase com a própria noção de diferenciação social, que implicava a independência do direito e da política, também, da instância moral. A implausibilidade da ideia de contrato social revelou-se na medida em que, no seio de concepções a princípio democráticas, como a de Rousseau, reapareceu uma noção de igualdade que se encontrava apoiada na desigualdade entre cidadãos e súditos, assim como reentrou numa noção de soberania que era, a um só tempo, popular e absoluta.

A ambiguidade do caráter jurídico do contrato social, que repousa no fato de ele ser um contrato jurídico anterior à diferença entre o jurídico e o não-jurídico, isto é, anterior ao próprio direito, deixa entrever a dificuldade que a vontade política tem em submeter-se a uma fundação e, portanto, também a uma limitação jurídica: a volonté génerale não conhece limites jurídicos. Para Hobbes, a solução ainda foi aquela de pressupor que o soberano é bom, justo e zeloso da vida e segurança de seus súditos. Supôs-se que o caráter jurídico do contrato social advém, ainda, do velho direito natural, mas que esse já não era um direito tão "verdadeiro" como aquele que emerge da vontade (absoluta) política. Nesse passo, as teses contratualistas fundavam-se numa naturalidade dos deveres, e sobretudo no primeiro dos deveres, aquele de obedecer. Já em Locke, o contrato, fundado numa antropologia positiva, na qual o homem é visto como portador, 
por natureza, de direitos, a limitação do exercício do poder político decorre, precisamente, dessa anterioridade do próprio direito natural. Na explicação de Locke, a natureza fez dos homens indivíduos livres e, acima de tudo, proprietários.

$\mathrm{O}$ paradoxo do contrato social, de como o direito pode encontrar um fundamento jurídico em um direito anterior a qualquer forma de direito, encontrou, portanto, na noção de indivíduo uma possibilidade de assimetria. Os indivíduos fundam o contrato social e, com isso, fundam o direito. Mas essa ideia, que pressupunha a noção de direitos humanos (direitos naturais) por sua vez também demonstrou ser paradoxal. Na medida em que o individualismo concebeu a humanidade dos indivíduos como expressão de uma natureza humana que, enquanto tal, é uma natureza de direitos, "direitos humanos", não é apenas os indivíduos que fundam o contrato social, e com isso o direito, mas é também o direito (natural) quem funda os indivíduos. ${ }^{4} \mathrm{~A}$ circularidade dessa formulação evidencia, novamente, o paradoxo da diferença entre direito e indivíduo, subjacente à noção de contrato social. O contrato pressupunha os indivíduos e seus direitos humanos, assim como a condição humana dos indivíduos pressupunha, por sua vez, o contrato.

Mas o que acontece com os indivíduos após o contrato? O contrato cria a diferença entre os direitos humanos, que lhe são anteriores, e os direitos constituídos, decorrentes do pacto. Tudo isso sob a base do paradoxo da unidade entre estado de natureza e estado civil. Desse modo, os direitos são concebidos como direitos que podem ser salvos do estado de natureza no estado civil, que sobrevivem a esta travessia, pois o contrato social não pode ser dissolvido. ${ }^{5} \mathrm{O}$ contrato se constitui tendo por pressuposto os direitos humanos, para depois servir de base à sobrevivência dos direitos humanos no estado civil.

A fragilidade de toda esta arquitetura teórica, sem dúvida nenhuma bastante engenhosa, revela-se em face da progressiva visibilização da contingência daquilo que resulta do pacto: o Estado e, também, o direito como direito estatal. Essa contingência pode, já na história das teorias contratualistas, ser verificada no fato de que o contrato social foi capaz de fundar tanto teses absolutistas (Hobbes, Rousseau) como constitucionalistas (Locke, Kant). Mas pode, também, ser constatada na medida em que, numa e noutra perspectiva, era o artifício do contrato que permitia a saída do estado de natureza para um estado civil que, como tal, podia ser transformado, ou melhor, revolucionado.

4 "Nicht die Individuen begrunden den Sozialvertrag, sondern der Soyialvertrag begrundet die Individuem". (LUHMANN, 1995, p. 232).

5 „Und dies nicht nach dem Muster von Naturzustand/Zivilsustand, sondern in der paradoxen Form der Einheit dieser Differenz. Menschenrechte sind die Rechte, die sich aus dem Naturzustand in den Zivilzustand hinuberretten können, und dies auch und gerade dann, wenn der Sozialvertrag unkundbar ist" (LUHMANN, 1995, p. 232). 
As revoluções rompem com os pressupostos jusnaturalistas do contrato social. O Estado é passível de revolução apenas se, em sua base, encontra-se o contrato social como algo que não é necessário, mas sim artificial. Se as bases jusnaturalistas do contrato social pressupunham a ideia de natureza universal dos direitos, a tradição não apenas era identificada como sendo a única ordem possível, mas também como sendo a expressão legítima dos direitos humanos.

Foi nesse contexto, de descoberta da contingência do contrato, que se forjou a noção de "Revolução". Revolução é um termo dotado de significados ambíguos, pois a ideia de ruptura que vem indicar é expressa mediante um retorno ao passado. Em 1842 um pensador francês apontou esse problema, recordando que uma revolução significava, originalmente e de acordo com o sentido literal, um movimento circular, uma volta que retorna ao ponto de partida do movimento. ${ }^{6}$ Já em 1789, a ideia de Revolução, no entanto, pareceu refletir uma preocupação com uma ruptura com o passado. Para Koselleck, desde 1789 a palavra revolução perdeu sua acepção original de volta ao passado, passando a indicar um futuro desconhecido...

A Revolução, desta forma, rompe com o círculo da tradição, para justificar-se posteriormente, como apelo ao futuro, em referência a um passado anterior àquele da monarquia absoluta, o passado do estado de natureza, da plenitude dos direitos do homem. O paradoxo da revolução é, então, o paradoxo da liberdade (lembra Koselleck que Robespierre prometeu a seus concidadãos "acelerar" a revolução para dessa forma conseguir a liberdade). A doutrina jusnaturalista, portanto, era muito mais adequada à afirmação da continuidade dos regimes tradicionais do que, propriamente, à fundação de uma ordem pós-revolucionária.

O problema que emergiu das revoluções foi, então, o de se encontrar um novo lugar para a fundação. A revolução retira, da formulação do contrato social, o véu de

6 Observa Koselleck (1993, p. 69-74) que esse conceito de revolução aparece na obra de Copérnico de 1543, De Revolutionibus orbium caelestium, para depois desembocar na política e na astrologia: "así como las estrellas trazan su curso circular independientemente de los seres humanos terrenales, pero influyendo también en los hombres o incluso determinándolos, del mismo modo también resuena desde el siglo XVII en el concepto político de revolución un doble sentido: las revoluciones se realizan por encima de las cabezas de los participantes, pero cada uno de los afectados queda prisionero de sus leyes". Nesse sentido usou Hobbes a palavra, sugerindo como negativa a circularidade que, na Inglaterra, levou à restauração da monarquia: "I have seen in this revolution a circular motion". Nessa direção, o conceito adquiriu um sentido político negativo, como sinônimo de guerra civil. No século XVIII a palavra revolução adquiriu um sentido positivo e tornou-se uma moda; a descrição da sociedade voltou-se para o aspecto de mudança e ruptura com o passado, de forma que a ideia de revolução se estendeu aos costumes, ao direito, à religião, à economia. Em 1172 afirmou Louis Sébastien Mercier que "tout est révolution dans ce monde ». Na opinião de Koselleck, essa moda refletia a experiência vitoriosa da Revolução na Inglaterra, de onde a constatação de Voltaire de que na Inglaterra havia verdadeiramente existido uma revolução, enquanto em outros países haviam existido apenas guerras e derramamento de sangue sem resultado algum. 
sua ambiguidade: a subversão da natureza das coisas não pode ser, por sua vez, natural. Quando desvelada a ambiguidade da noção de contrato social, é que se pensou num vínculo jurídico e não natural ao poder, inventando-se a Constituição e "declarando", ou seja, positivando, os direitos.

3.

As modernas Constituições, assim como as declarações de direitos, parecem ter cumprido o importante papel de oferecer uma nova fundação, para além da noção de contrato, para o direito e para a política. Nas Constituições, a soberania, na forma da "soberania popular", é domesticada; ao passo que os direitos, nas declarações, libertam-se de seus condicionamentos naturais, indo ao encontro da contingência. A soberania popular foi, nas Constituições, domesticada mediante a positivação dos direitos. Essa operação radical pressupôs a identificação da política com a moral burguesa, da qual o Iluminismo derivou a crença na possibilidade de uma planificação do futuro. A crença na possibilidade de planificação foi o pressuposto da estabilização da nova ordem social e o projeto revolucionário francês tornou-se, dessa forma, um projeto de revolução social. ${ }^{7}$ Não é apenas o ancien régime que deveria ser definitivamente sepultado, mas também toda uma visão de sociedade e Estado, fundada na tradição, que precisava ser abandonada.

A nova solução consistiu em projetar o direito e a política em direção ao futuro. Ideias como "nação", "direitos humanos", "liberdade", "igualdade" e "democracia" são ideias que - modernizadas - foram fundamentais para essa projeção da política e do direito no futuro. Nisso consistiu o giro semântico que tais expressões, antigas no vocabulário político-jurídico, alcançaram com a fundamentalização e posterior positivação da noção de direitos humanos. As soluções "direitos humanos" e "Constituição" foram concomitantes e, não necessariamente, excludentes, como havia pensado Rousseau. Os direitos humanos, antes pano de fundo do contrato social, transformaram-se num texto de direito positivo que, por sua vez, encontrou seu fundamento na supralegalidade constitucional. Assim que a Declaração de Direitos do Homem e do Cidadão, de 1789, foi recebida pela Constituição Francesa de 1791 em seu preâmbulo.

Essa solução foi precedida, na trilha de Rousseau, por um longo debate acerca da necessidade do vínculo constitucional, no qual se revelou o antagonismo entre os direitos humanos e a soberania popular. Nesse debate, colocam-se Kant e Rousseau em posições contrárias, ainda que ambos alicerçados numa concepção de direitos humanos. No opúsculo "Beantwortung der Frage: Was ist Aufklärung?", aquele que Marx chamou

7 Em 1794, Wieland anotou que o propósito dos jacobinos era fazer da Revolução francesa uma revolução social, ou seja, uma reversão de todos os Estados existentes. (KOSELLECK, 1993, p. 78). 
de "o filósofo alemão da Revolução Francesa", Immanuel Kant, rejeitou veementemente a ideia de que uma época possa vincular outra, o que seria um impedimento ao processo de Ilustração. A questão dos "vínculos com o futuro" coloca-se, na perspectiva do autor alemão, como um obstáculo ao processo de ampliação dos conhecimentos e depuração dos erros, ou seja, de esclarecimento. Para Kant, a admissão de tais vínculos "seria um crime contra a natureza humana, cujo destino primordial consiste, justamente, neste progredir". (KANT, 1993, p. 17) O processo de Ilustração é visto por Kant como emancipação, ou seja, como o processo mediante o qual o homem vai-se liberando da sua condição de "menoridadade", adquirindo sua autonomia. A condição de menoridade teria sido o pressuposto de um Estado absoluto em que, como déspota esclarecido, o soberano apresentou-se como o Rei-Pai. Nesse passo, os súditos eram "autoculpáveis" de sua condição de menoridade, "na falta de decisão e valor para servir-se por si mesmo sem ser guiado por outrem".

Mas Kant admite que, no caso do vínculo constitucional, tal ameaça não se faz presente. Kant, diferentemente de Rousseau, apresenta um argumento contrário aos vínculos com o futuro que, na verdade, transforma-se num argumento a favor deles: ou seja, a favor da Constituição. Todos os acordos aceitos de modo "incompetente ou ultrajante", em prol da Ilustração, poderiam legitimamente ser rechaçados pela posteridade. A pedra de toque, para Kant, já não é mais simplesmente o problema de uma nova vinculação. $O$ problema é como operar uma nova forma de vinculação, não mais com o passado, mas agora com o futuro. E, afinal, este é também um velho problema, aquele relativo à possibilidade de um soberano vincular a si mesmo. "De tudo o que se pode decidir como lei para um povo reside a seguinte pergunta: poderia um povo impor a si mesmo semelhante lei?". (KANT, 1993, p. 23)

A resposta de Kant é favorável à ideia de um vínculo especificamente jurídico ao exercício do poder, isto é, é favorável à ideia de Constituição. Um povo pode impor-se uma lei capaz de vincular tanto a si mesmo quanto às gerações posteriores se esta fosse uma lei "melhor" para a introdução de uma nova ordem que, limitando a liberdade, a garantisse, deixando livres os cidadãos - "especialmente os sacerdotes, enquanto doutos" para se manifestarem publicamente acerca das deficiências desta ordem ${ }^{8}$. Portanto, corolário desta liberdade é a ideia de que a ordem estabelecida por uma Constituição não pode ser uma ordem imutável. Ninguém está autorizado, diz Kant, a colocar freios ao processo de Ilustração sem que isto signifique "violar e pisotear" os direitos humanos. $\mathrm{E}$ isto ainda que, naquilo que concerne a sua pessoa, possa o indivíduo eludir o processo

8 "Esto sería posible si tuviese la esperanza de alcanzar, en corto y determinado tiempo, una ley mejor para introducir un nuevo orden, que, al mismo tiempo, dejara libre a todo ciudadano, especialmente a los sacerdotes, para, en cuanto doctos, hacer observaciones públicamente, es decir, por escrito, acerca de las deficiencias de dicho orden". (KANT, 1993, p. 22). 
de ilustração, apenas por certo tempo e em determinadas matérias. ${ }^{9} \mathrm{E}$, se um povo não pode decidir em relação a todas as matérias por si e para si mesmo, com mais razão também está impedido de proceder dessa forma um monarca em seu nome, "pois sua autoridade legislativa reside, precisamente, no fato de toda a vontade do povo encontra-se reunida na sua própria”. (KANT, 1993, p. 23) Kant, com isto, defende a posição de um monarca "ilustrado", que tem como dever não prescrever nada a seus súditos em matéria de religião: este é um princípe tolerante, ou seja, ilustrado.

Na tradição do republicanismo, a ideia de que o consenso dos pais pode vincular seus filhos até a mais longínqua geração não é aceitável. Para um republicano, "nenhuma instituição, por mais importante que seja, é inalterável; nenhuma lei é tão fundamental ao ponto de não poder ser derrogada". (HOLMES, 1998, p. 198) Essas premissas republicanas finalmente foram consagradas no art. 28 da Constituição Francesa de 1793, quando nele se inscreveu aquela formulação rousseauniana de que uma geração não pode sujeitar as gerações futuras às suas leis.

Tal debate, colocado no contexto em que a saída possível para a estabilização era a ruptura com o Ancien Règime, no caso da França, e com o parlamento inglês, no caso dos Estados Unidos, trazia um problema que era ligado à dimensão temporal da fundação da diferença da unidade entre direito e política. Nessa discussão, grande importância teve a obra de Thomas Paine, sobretudo o opúsculo Common Sense ${ }^{10}$ que, somente no ano de 1776, foi editado vinte e cinco vezes. ${ }^{11}$ Paine, para quem democracia é um governo dos "vivos", colocou o princípio democrático como superior a qualquer vínculo constitucional, afirmando que ninguém possui um direito que vincule as futuras gerações, visto que cada época e cada geração devem ter para si mesmas a mesmíssima liberdade de escolha que tiveram as épocas e gerações precedentes. (HOLMES, 1998, p. 199) Contra Paine, Edmund Burke objetou que o Parlamento inglês de 1688 havia vinculado legalmente seus sucessores até o fim dos tempos. Burke, na sua Reflexões sobre a Revolução em França, atacou a invenção constitucional do século XVIII, aconselhando

9 “En lo que concierne a su propia persona, un hombre puede eludir la Ilustración, pero sólo por un cierto tiempo en quellas materias que está obligado a saber, pues renunciar a ella, aunque sea en pro de su persona, y con mayor razón todavía para la posteridad, significa violar y pisotear los sagrados derechos de la humanidad". (KANT, 1993, p. 22).

10 “No referido opúsculo, Paine não se limita a tecer argumentos favoráveis à independência: pelo contrário, inicia o ensaio por perquirir a origem e a finalidade dos governos em geral, para, a seguir, rejeitar a Monarquia e a sucessão hereditária, condenam não apenas as políticas coloniais da Coroa britânica, mas a própria e tão decantada "Constituição brutânica"e, insurgindo-se contra as teses de Locke, de Montesquieu e contra todas as hierarquizações presentes no modelo liberal originário, ataca os mecanismos típicos do chamado governo misto ou equilibrado, entre os quais, a existência de uma Câmara Alta e a participação constitutiva do Chefe de Estado no procedimento legislativo". (CARVALHO NETTO, 1992, p.89-90).

${ }^{11}$ De acordo com Eric Foner, Tom Paine and Revolutionary America. New York: Oxford University Press (apud CARVALHO NETTO, Op. Cit., p. 89). 
seus compatriotas a manterem-se presos à concepção inglesa de Constituição, fundada na tradição. ${ }^{12}$

Na Revolução Norte-Americana, o problema dos vínculos ao poder apareceu, portanto, em face da necessidade de se deslocar, na situação de estabilização da independência, a sede da soberania do parlamento inglês para o povo americano. Mas a América praticou a revolução, paradoxalmente, sob a premissa tipicamente inglesa (e medieval) de que ao soberano não é permitido violar o direito. ${ }^{13}$ As posições de Burke e Paine têm seu ponto de antagonismo exatamente no modo com que cada qual olha para a tradição; enquanto para Burke o passado era um capital de sabedoria acumulada, para Paine a tradição nada mais era do que uma "cloaca pestilenta de abusos". (HOLMES, 1998, p. 199) Nesse sentido, democracia para Paine (que, neste ponto específico, está de acordo com Locke), significava abertura em relação ao futuro (o que exclui a ideia de vínculo constitucional, ou melhor, implica a institucionalização da mutabilidade da própria Constituição). Num contexto de ruptura com a tradição, o direito e a política não poderiam mais encontrar naquele passado, com o qual se rompeu, por meio da revolução, o fundamento de sua legitimidade. Em resposta à posição anticonstitucionalista de Jefferson e Paine, Madison defendeu os compromissos com o futuro estabelecidos mediante a Constituição.

$\mathrm{O}$ argumento da autovinculação como uma não vinculação, que já despontara em Bodin, reapareceu na defesa que Madison faz da Constituição. Tanto quanto para Bodin a garantia do caráter ilimitado da soberania absoluta estava na aceitação de certos limites externos, para Madison os vínculos constitucionais ao poder não representam, necessariamente, amarras para este; antes, eles podem promover e não tanto restringir a ação do agente livre: "A Constituição americana não é um obstáculo ao governo, mas um instrumento de governo. Não é um peso, mas uma força”. (HOLMES, 1998, p. 200)

O deslocamento da sede da soberania, aqui, é claramente a estratégia estabilização daquela nova ordem, de modo que a "a Constituição representativa não é outra coisa que

12 "Não tendo sido iluminados por essa luz que, ao que pretendem, tanto ilumina esses senhores na França, os que nos antecederam levaram em consideração nas suas ações um sentimento profundo de consciência da ignorância e da falibilidade da humanidade. O que os criou assim tão cheios de falhas, os recompensou por terem levado em conta, em suas próprias maneiras de agir suas características naturais. Devemos imitar a prudência de que faziam prova se quisermos conseguir um destino semelhante ao que tiveram ou então conservar o que deixaram, e, mantendo-nos no sólido terreno da Constituição Britânica, podemos admirar, sem contudo, procurar seguir, o vôo desesperado dos aeronautas franceses". (BURKE, 1997, p. 222).

13 "In América la rivoluzione viene fondata giuridicamente sull'idea ancora medioevale per cui al sovrano qui il Parlamento londinese - non è lecito violare il diritto. Sotto la formula generale della sovranità, il principe, oggetto della resistenza, è sostituito dal Parlamento ora sovrano. Ma proprio il fatto di continuare a pensare il Parlamento in termini di rappresentanza popolare fa sorgere nuove difficoltà. La teoria della rappresentanza debe assumere nuove forme. È necessario distinguere tra il popolo come corpo collettivo e il popolo come copo rappresentativo. Già prima del Settecento, gli Inglesi avevano preso atto della dislocazione della sede della sovranità, traendone tutte le conseguenze”. (LUHMANN In: ZAGREBELSKY, PORTINARO e LUTHER, 1996, p 87). 
a inquietude fixa, a revolução detida, o estado absolutamente sujeitado" (LUHMANN, 2002 , p. $547^{14}$ ), apresentando-se como uma "estabilidade dinâmica".

Nas Constituições, o paradoxo da unidade da diferença entre direito e política não se resolve mais mediante a antiga hierarquia entre direito divino, natural e positivo, como o fora quando da afirmação do Estado a soberania absoluta, mas sim por meio da definitiva afirmação da positividade do direito, de modo tal que uma nova diferenciação tornou-se necessária: o direito positivo bifurca-se em direito intangível e direito disponível. Para Luhmann, o que está em jogo aqui, tanto para o sistema jurídico quanto para o sistema político, é uma nova modalidade de diferenciação entre heteroreferência e autorreferência nas operações internas do sistema. Nesse passo, a Constituição nada mais significa que "o dispositivo voltado para diferenciar a autoreferencialidade da heteroreferencialidade nas operações internas do sistema”. (LUHMANN, 1996, p. 107)

A Constituição, vista da perspectiva do direito, apresenta-se como substituto funcional da noção de direito natural, precisamente constitucionalizando, isto é, "positivando" os outrora denominados direitos naturais. Vista da perspectiva do sistema político, a Constituição é a sede onde o direito absoluto do monarca - sua soberania faz-se substituir pelo reconhecimento do direito dos cidadãos como limite ao exercício do poder político. Nessa dupla perspectiva, a Constituição limita e cria espaços de liberdade para ambos os sistemas, jurídico e político. Essa paradoxal função de criação e limitação das liberdades consentidas aos sistemas, nas Constituições, refletiu-se na diferença entre direitos humanos e direitos fundamentais. No século XVIII, essa diferença terminológica veio sugerir que os direitos fundamentais são os direitos de liberdade positivados em uma ordem jurídico-política concreta, isto é, em um determinado Estado, ao passo que "Unter Menschenrechten verstehen wir dagegen solche Rechte, die dem Menschen kraft seine personalen Wurde von Natur aus zukommen (sollen)". ${ }^{15}$

Encaradas sob esse prisma as Constituições, a diferença entre direitos humanos e direitos fundamentais que por meio delas se afirmou, manifesta-se também como uma diferença temporal. O direito, sobretudo "os direitos" constitucionalmente estabelecidos são válidos porque, fundados na Constituição, deixam-se projetar para o futuro de tal forma que, exatamente por isso, podem ser "efetivados" no presente. Essa não é, ademais, uma característica exclusiva das normas estabelecedoras de direitos cuja concretização, muitas das vezes, é retardada em face de obstáculos não necessariamente jurídicos; em face da escassez econômica, por exemplo. A contínua projeção do direito no futuro não resulta do caráter "programático" deste, mas sim de sua própria função: aquela de criar vínculos

${ }^{14} \mathrm{O}$ autor refere-se, aqui, a uma passagem de Friedrich Schlegel (1984).

${ }^{15}$ Como observa Christoph Link, "Die Idee unveräußlicher Menschenrechte ist daher immer mit naturrechtlichen Vorstellungen verbunden, während Grundrechte nicht notwendig als Konkretisierung derartiger naturrechtlicher Postulate verstanden werden mussen". (LINK In: BIRTSCH, 1987, p. 217). 
com o futuro. Esse atrelamento do futuro mediante o direito, a contrário do que se pensa comumente, não significa uma determinação de sentido sob o plano material. $O$ fato de o direito permanecer incerto, duvidoso em relação à sua "efetivação plena", não significa que esse seja menos direito. Importa, exatamente, que decisões presentes sejam tomadas com base naquelas expectativas futuras que, por sua vez, podem vir a não se realizarem.

Por isso, ainda que, de maneira surpreendente, os direitos apontem sempre para uma generalização "ideal” na dimensão social e material da comunicação, ou seja, apontem sempre para um futuro que, enquanto tal, jamais se realizou, resta perfeitamente compatível com essa ideia a concepção de que tais direitos são uma manifestação da natureza humana. Observe-se que, mesmo nos textos de direito positivo, os direitos humanos permanecem sendo indicados como direito natural, porque os textos apresentamse como declarações de direitos anteriores aos próprios textos, como se pode ver da utilização do verbo "ser" nessas declarações: os homens são livres, são iguais, são proprietários... ${ }^{16}$ Não surpreende, portanto, que às declarações de direitos tenha se sucedido a fundamentalização desses, com sua positivação nas Constituições. Luhmann observa, a esse propósito, que o Bill of Rights inglês não trouxe nenhuma inovação sob o plano do conteúdo, descrevendo, apenas, uma situação que jurídica evidentemente já existente, de forma que "à fundamentalização dos direitos individuais promovida na Inglaterra dos seiscentos seguiu-se, simplesmente, a sua constitucionalização". ${ }^{17}$

Assim, nas Constituições, a diferença da unidade entre direito e política, que a modernidade nascente descrevera como a contraposição entre direito de resistência e razão de Estado e, mais tarde, na contraposição entre soberania popular e constitucionalismo, reapareceu como o paradoxo da diferença entre a liberdade dos direitos humanos e a liberdade como direito positivado. Foi ao enfrentar paradoxos desse tipo que, de um lado, Kant combateu o ideal republicano de democracia tanto quanto, de outro, Rousseau combateu o constitucionalismo. No quadro de uma ordem constitucional, a democracia só poderia apresentar-se como "representativa", assim como a Constituição só poderia ser vista como um vínculo da vontade popular com o futuro que, no entanto, poderia ser sempre revisto pelas gerações também futuras.

A Constituição, neste passo, foi vista como um compromisso (como uma promessa compactuada) que poderia ser revisto de acordo com processos institucionalizados, de maneira a garantir-se que o fato de esta ser um texto que projeta sua legitimidade no futuro

16 "Eine Zeitlang kann man sich daruber hinweghelfen, indem man das, was die Texte meinen, immer noch als ,Naturrecht' bezeichnet und diese Referenz auf Natur auch in den Textformulierungen anklingen lässt, es in sie hineinlegt und dann wieder herausholt, etwa mit ,'ist' - Formulierungen (statt ,soll' - Formulierungen), zum Beispiel in Art. I GG". (LUHMANN, 1995, p. 233).

17 "Per esprimersi com Gerald Stourzh, si potrebbe aggiungere che allá fondamentalizzazione dei diritti individuali avviata nell'Inghilterra del Seicento seguirà semplicemente la loro costituzionalizzazione”. (LUHMANN, 1996, p. 84-85). 
não pudesse dela fazer um direito destinado a tornar-se velho. Nesta direção, foram estabelecidos procedimentos específicos para a transformação da Constituição, introduzindose aquela diferença entre direito constitucional e "outro direito", o que produziu uma diferença no que diz respeito à abertura temática de um direito que já não se deixa determinar pelo direito natural, mas encontra sua moldura na noção de Constituição.

Ao mesmo tempo, tudo isso também significa a novidade daquela estratégia, ou seja, aquela nova forma de se lidar com a dimensão material do sentido por um deslocamento no plano temporal e social. Essa nova estratégia da autolegitimação do direito e da política, que se apresentou como vínculo com o futuro, retomava velhos problemas dos vínculos com o passado: só que, se antes o passado era uma cadeia que servia de freio para a mudança social, o futuro, como promessa de mudança social, permanece como uma miragem, algo que não é jamais alcançado. Mais que isto: o futuro permanece sendo futuro, sempre, em relação a um presente. $\mathrm{O}$ que significa, o futuro só tem sentido como significante do presente. Vale dizer: mais que "promessas", as normas constitucionais são compromissos que, ainda que não se realizem, tornam possível a tomada de decisões no presente. Assim, com o deslocamento da sede da soberania na dimensão temporal, as Constituições estabeleceram uma modalidade de vínculo que, no plano material, também era nova: estes eram vínculos que, mais do que vínculos para o futuro, são vínculos com o futuro. ${ }^{18}$ Isso significa que o futuro não estava predestinado a se transformar num equivalente funcional da tradição, isto é, num horizonte de sentido passado. O futuro, assim, não era necessário; este permanecia contingente e incerto, na medida em que ele vincula não a si mesmo, mas tão somente o presente. $\mathrm{O}$ futuro das Constituições é futuro presente.

Como estratégia de autofundação do direito e da política, as Constituições cumpriram um importante papel na modernidade: aquele de integrar, ainda que de forma precária e artificial, as pretensões de fechamento do direito e da política, ou seja, a integração da diferença entre direito e política. ${ }^{19}$ A invenção das Constituições consistiu no passo que consentiu ao direito e à política uma estrutura comum, a um só tempo política e jurídica, capaz de indicar tanto a submissão do direito à política quanto a desta, por sua vez, ao direito. Essa espécie de entrelaçamento dos sistemas da política e do direito apresenta, ainda em nossos dias, uma forma específica de circularidade: por meio do poder, a política produz direito ao mesmo tempo em que o direito pode controlar a legitimidade jurídica das decisões políticas. Em outros termos, o poder submete-se ao controle do direito que o poder mesmo produz. Resolve-se, dessa forma, aquela tensão entre direito e política mediante a introdução da Constituição como ligação entre política

\footnotetext{
${ }^{18}$ Nesse sentido, e da perspectiva da Teoria dos Sistemas: DE GIORGI, 1998.

${ }^{19}$ Que, por isso, é vista por Luhmann como uma estratégia de "desparadoxação".
} 
e direito. Esta ligação exclui supremacia de uma ou outra parte; ela pressupõe uma grande variedade estrutural do direito e, ao mesmo tempo, uma universalização dos temas da decisão política. Isso quer dizer que, mesmo no contexto da afirmação da Constituição, assim como não há uma política suprema, não existe, também, um direito supremo: ambos são, a um só tempo, livres para dispor sobre suas próprias limitações. Essa recíproca supremacia de direito e política, ou essa recíproca submissão de direito e política, no entanto, não poderia significar uma não diferenciação. Isso quer dizer, apenas, que o sistema da política, por suas decisões, refere-se sempre a si mesmo, assim como o direito, por suas operações, utiliza sempre e apenas o direito: esses são sistemas funcionalmente diferenciados.

As diferenças comunicativas entre direito e política parecem desaparecer sob o "véu" das Constituições mas, na verdade, permanecem. "A Constituição constitui e, ao mesmo tempo, torna invisível o acoplamento estrutural de direito e política". (LUHMANN, 1996, p. 101) Com isso, Luhmann pretende indicar que, na Constituição, a positivação do direito e a democratização da política apoiam-se reciprocamente, dificultando a visualização de que o sistema jurídico e o sistema político são sistemas funcionalmente diferenciados. No contexto da diferenciação funcional, a questão do limite e, portanto, da fundação dos sistemas, deixou de encontrar respostas plausíveis em algo que se encontrasse fora do sistema, seja na natureza, seja em deus, seja na razão ou nos homens. Os sistemas jurídico e político reconstruíram, na forma de um acoplamento estrutural, esses limites. Este acoplamento estrutural, precisamente a Constituição, fundou uma organização que é, a um só tempo, jurídica e política, mas que não é, por isso, nem a totalidade da política e nem a integralidade do sistema jurídico: o Estado de Direito. Com o conceito de Estado, não se tratou de indicar apenas um único sistema: o Estado é uma organização pertinente a dois diferentes sistemas, operativamente fechados, com funções próprias e distintas, com programas diferentes e dependentes, cada qual, de seu próprio código da comunicação. A relação que as Constituições estabeleceram entre política e direito pressupõe, portanto, a diferenciação da circularidade que existe entre política que produz direito e legitimação jurídica da decisão política. ${ }^{20}$ Da perspectiva de cada sistema, direito e política, a Constituição foi observada de diferentes formas, como solução de diferentes problemas sociais.

${ }^{20}$ Isto è particolarmente evidenciado pelo trattamento diferenciado que cada sistema, direito e política, dão aos conceitos constitucionais que lhes são comuns. "Si deve dunque distinguere: la costituzione utilizza concetti come popolo, elettore, partiti politici, Stato rinviando in tal modo alla politica. Questi tuttavia, in quanto concetti del testo costituzionale, non possono essere altro che concetti giuridici eventualmente riducibili a contenuti giudiziabili. Nel caso di una descrizione esterna del sistema giuridico, la stessa fattispecie può tuttavia essere formulata in modo diverso. Rinvii al sistema politico stabiliscono nello stesso tempo un accopiamento strutturale tra sistema giuridico e sistema politico che si pone "ortogonalmente" alle operazioni interne al sistema e non può essere da queste afferrato”. (LUHMANN, 1996, p.100-101). 
Nesse sentido, também os direitos humanos, fundamentalizados nas Constituições, adquiriram diferentes significados para o direito e para a política. Para o sistema jurídico, dado que a Constituição é a lei suprema, os direitos se colocam como o fundamento da própria Constituição; para o sistema político, por sua vez, os direitos são, tanto quanto a Constituição, um instrumento político, "no duplo sentido de política instrumental modificadora de situações - e de política simbólica - não modificadora de situações". (LUHMANN, 2002, p. 548)

Ocorre que, nas condições da sociedade moderna, os direitos humanos, vistos tanto como fundamento do direito quanto como instrumento da política, não estão em condições de estabelecer uma convergência entre uma coisa e outra, não são capazes de integrar direito e política. $\mathrm{E}$ isso ocorre não apenas em vista do clássico conflito entre os direitos de liberdade e o direito à igualdade, ou ainda em vista da tensão entre soberania popular e direitos humanos.A não convergência decorre do fato de que direito e política, na sociedade moderna, são dois diferentes sistemas sociais, voltados para a solução de diferentes problemas sociais. Nesse contexto, os direitos são interpretados de modo diversos por esses diferentes sistemas sociais, direito e política. Na verdade, a possibilidade de que os sistemas pudessem realizar "trocas", tais como proteção dos cidadãos em face dos interesses do Estado ou controle judicial da constitucionalidade das leis, não se torna possível porque foi inventada a Constituição e, com ela, foi estabelecido o princípio da separação dos poderes ou a proteção dos direitos individuais: isto ocorre, diz Luhmann, "devido à diferenciação entre os sistemas jurídico e político cada um dos quais se ocupa de maneira diversa dos paradoxos". (2002, p. 548)

Isso explica por que, em inúmeras situações da política, a afirmação dos direitos humanos parece exercer um papel muito mais simbólico. Luhmann chega mesmo a afirmar ser plausível a hipótese de que, em alguns países, as Constituições possam servir muito mais como um instrumento de política simbólica, em decorrência do fato de que naquelas regiões o direito não tenha se fechado operativamente de modo a tornar-se impermeável à influência da política e de outras forças sociais. (LUHMANN, 2002, p. 430)

A operacionalização de uma política simbólica, no entanto, não é uma consequência de uma não diferenciação funcional. Parece-nos mais adequado descrever igualmente esta capacidade de simbolização política pelo direito - via constitucionalização - também como uma estranha, e aparentemente negativa, prestação que o direito oferece à política. Com isso, queremos salientar duas distintas questões. Primeiro, o entendimento de que a instrumentalização da Constituição contra a Constituição (e portanto, em desfavor da 
realização dos projetos constitucionalmente traçados), não é um privilégio dos países semidesenvolvidos ou das chamadas "periferias da modernidade" ${ }^{21}$. Em segundo lugar, é de se observar que a possibilidade da política lançar mão desta prestação que lhe é disponibilizada pelo direito é, exatamente, resultado da diferenciação dos dois sistemas. Diferente seria o caso de corrupção dos sistemas, também muito frequente nas periferias da modernidade (que podem contingencialmente "localizar-se" num grande centro urbano europeu ou numa favela do Rio de Janeiro), quando um sistema se recusa a funcionar com base em seu próprio código, tomando decisões referidas aos códigos de outros sistemas: hipótese que inclui situações que vão desde a compra de decisões judiciais até a tomada de decisões pretensamente "justas" e não necessariamente jurídicas, por exemplo.

5.

Nessa latência da diferença entre direito e política, sob a referência comum aos direitos humanos, emerge novamente o caráter paradoxal destes. Antes que integrar direito e política, é no campo dos direitos humanos que as diferenças entre esses dois sistemas mais se expressam. Para que os "direitos humanos" sobrevivam às Constituições e à chamada crise da soberania, é preciso encontrar, para estes, novos fundametos: não mais no direito natural e, também, não mais na fundamentalização constitucional. Fala-se, então, em internacionalização e num cosmopolitismo fundado na noção de direitos humanos.

No contexto de uma sociedade globalizada, os “direitos humanos' parecem tender a vencer a luta com a soberania. A noção de direitos revela-se, de forma inédita, capaz de desvincular-se das referências territorias, políticas e jurídicas atinentes à noção de Estado. Cada vez mais, vislumbra-se que a expectativa entorno aos direitos humanos é de que estes transcendam as fronteiras dos Estados, do poder e do direito estabelecido. Da mesma forma, reacendem-se velhas esperanças de que, pela via dos direitos humanos, a sociedade moderna possa encontrar um caminho para sua integração. Ou seja, que não apenas direito e política, mas também os outros sistemas sociais, como a economia ou a educação, possam se deixar regular pelo primado dos direitos humanos.

De fato, a emergência da moderna noção de direitos humanos representou, como se pode colher da história semântica dos conceitos de liberdade, igualdade e propriedade, numa reação à moderna forma de diferenciação social. É á medida em que a diferenciação se acentua, conformando uma sociedade funcionalmente diferenciada, que os direitos humanos se condensam. Primeiro como expectativas de diferenciação, como, por

${ }^{21}$ A noção de "periferia" não guarda, na teoria dos sistemas, qualquer referência espacial. Numa cidade como o Rio de Janeiro, por exemplo, encontramos formas periféricas e, também, centrais de produção de sociedade. Em Frankfurt ou Berlim, também. 
exemplo, no clamor pela liberdade política como garantia de imunidade política em face da religião, ou ainda a afirmação da liberdade econômica, voltada a uma garantia de economia capitalista em vista das reivindicações de distribuição da riqueza. Contemporaneamente, no entanto, os direitos passam a representar, e portanto a simbolizar, a possibilidade de uma nova integração. Como reação à diferenciação social, torna-se plausível e até mesmo legítimo pensar-se no direito, e mais particularmente nos direitos como "sistema de direitos" como "meio da integração social". ${ }^{22}$ Mas precisamente aqui revela-se, novamente, o caráter paradoxal dos direitos humanos: só é possível a integração sob a base da desintegração, do "desencantamento" e da diferenciação.

Os direitos humanos, ao tempo em que pressupõem a diferenciação social, prometem precisamente a superação desta. Nesse passo, suas promessas não podem ser cumpridas, dadas as condições estruturais da sociedade moderna. Daí que faz sentido o apelo aos direitos apenas em face de sua violação. Quando uma escola funciona bem e oferece educação de qualidade aos seus alunos, não se clama por direitos humanos. Mas este é o tema da comunicação quando as promessas de uma boa educação não é cumprida pelos responsáveis e, então, faz sentido falar em "direito à educação". Isso revela a medida em que, na sociedade moderna, os direitos humanos assumam um caráter simbólico.

Tal fato encontra maior visibilidade nas chamadas "periferias da modernidade", onde a diferenciação funcional ainda encontra resistências. Aqui, a fórmula "direitos humanos" apresentou grande força simbólica: e isso tanto para a política quanto para o direito. O símbolo pode adquirir um caráter positivo de idealidade, mas pode, também, assumir contornos de um mecanismo de ocultação, de invisibilização, daquilo que a sociedade recusa-se a observar em si mesma, num sentido bastante negativo.

Em ambos os sentidos, positivo e negativo, a ficção dos direitos humanos, para usar a expressão de Agnes Heller, se não é uma realidade, produz realidades. Com isso, afirmamos que os direitos humanos, em que pese sua natureza paradoxal, é capaz de se desenvolver operativamente. Nesse quadro, passa a ser relevante não mais a busca pelos fundamentos dos direitos humanos ou pelas promessas feitas, em nome dos direitos humanos, que não foram cumpridas. Relevante e urgente é, todavia, observar a sério aquilo que se produz em nome dos direitos humanos.

\section{REFERÊNCIAS}

BLACKSTONE, William. Commentaires on the Laws of England. London: Dawsons of Pall Mall, 1966.

BURKE, Reflexões sobre a Revolução em França. Brasília: Editora Universidade de Brasília,1997.

${ }^{22}$ Para Habermas, "Solo nel caso in cui la crisi dello Stato di diritto se presentasse senza vie d'uscita, la forza d' integrazione sociale del diritto si rivelerebbe come strutturalmente insuficiente". (1996, p. 515). 
CARVALHO NETTO, Menelick. A sanção no procedimento legislativo, Belo Horizonte: Editora Del Rey, 1992.

DE GIORGI, Raffaele. Direito, Democracia e Risco: vínculos com o futuro, Porto Alegre: Sérgio Fabris, 1998.

HABERMAS, Fatti e norme, Contributi a una teoria dicorsiva del diritto e della democrazia. Milano:Guerini e Associati, 1996.

HOLMES, Stephen. Passioni e Vincoli. I fondamenti della democrazia liberale. Torino: Edizioni di Comunità, 1998

JELLINEK, Georg. La declaración de derechos del hombre y del ciudadano. Estudio de historia constitucional moderna. Trad. Adolfo Posada. Madrid: Librería G. De Vitoriano Suàrez, 1908.

KANT, Immanuel."Respuesta a la pregunta: ?Que es la Ilustracion?” in: ? Que es la ilustracíon?. Madrid: Tecnos, 1993

KOSELLECK, Reinhardt. Futuro pasado. Para uma semántica de los tiempos históricos. Barcelona: Buenos Aires, México: Ediciones Paidós, 1993.

LINK, Christoph "Naturrechtliche grundlagen des Grundrechtsdenkens in der deutschen Staatsrechtslehre des 17. und 18. Jahrhunderts" in BIRTSCH, "Gewissensfreiheit als Argument in England vom 16. zum 18. Jahrhundert" In: Grund- und Freiheitsrechte von der ständischen zur spätburgerlichen Gesellschaft. Göttingen: Vandenhoeck \& Ruprecht, 1987.

LUHMANN, Niklas. "Das Paradox der Menschenrechte und drei Formen seiner Entfaltung" In: Soziologische Aufklärung, Opladen, Westdeutscher Verlag 1995

LUHMANN, Niklas. "La costituzione come acquisizione evolutiva". In: ZAGREBELSKY, Gustavo; PORTINARO, Pier Paolo e LUTHER, Jorg. Il Futuro della Costituzione. Torino: Einaudi, 1996.

LUhmanN, Niklas. El Derecho de la Sociedad. Trad. Javier Torres Nafarrate.México, DF: Universidad Iberoamericana, 2002.

STOURZH, Gerald. "The Declaration of Rights, popular sovereignty and the supremacy of the constitution: divergencies between the American and the French Revolutions" in La Révolution Américaine et l"Europe. Colloques Internationaux du Centre National de la Recherche Scientifique, n. ${ }^{\circ}$ 577, Paris: Éditions du CNRS, 1979. 